\title{
PPAR- $\gamma$, Microglial Cells, and Ocular Inflammation: New Venues for Potential Therapeutic Approaches
}

\author{
Fiorella Malchiodi-Albedi, ${ }^{1}$ Andrea Matteucci, ${ }^{2}$ Antonietta Bernardo, ${ }^{1}$ and Luisa Minghetti ${ }^{1}$ \\ ${ }^{1}$ Department of Cell Biology and Neurosciences, Istituto Superiore di Sanità, 00161 Rome, Italy \\ ${ }^{2}$ G.B. Bietti Foundation for Ophthalmology (IRCCS), 00198 Rome, Italy
}

Correspondence should be addressed to Luisa Minghetti, luisa.minghetti@iss.it

Received 9 December 2007; Accepted 25 January 2008

Recommended by Suofu Qin

The last decade has witnessed an increasing interest for the role played by the peroxisome proliferator-activated receptor- $\gamma$ (PPAR$\gamma$ ) in controlling inflammation in peripheral organs as well as in the brain. Activation of PPAR- $\gamma$ has been shown to control the response of microglial cells, the main macrophage population found in brain parenchyma, and limit the inflammation. The antiinflammatory capacity of PPAR- $\gamma$ agonists has led to the hypothesis that PPAR- $\gamma$ might be targeted to modulate degenerative brain diseases in which inflammation has been increasingly recognized as a significant component. Recent experimental evidence suggests that PPAR- $\gamma$ agonists could be exploited to treat ocular diseases such as diabetic retinopathy, age-related macular degeneration, autoimmune uveitis, and optic neuritis where inflammation has relevant role. Additional PPAR- $\gamma$ agonist beneficial effects could involve amelioration of retinal microcirculation and inhibition of neovascularization. However, PPAR- $\gamma$ activation could, in some instances, aggravate the ocular pathology, for example, by increasing the synthesis of vascular endothelial growth factor, a proangiogenic factor that could trigger a vicious circle and further deteriorate retinal perfusion. The development of new in vivo and in vitro models to study ocular inflammation and how to modulate for the eye benefit will be instrumental for the search of effective therapies.

Copyright ( $) 2008$ Fiorella Malchiodi-Albedi et al. This is an open access article distributed under the Creative Commons Attribution License, which permits unrestricted use, distribution, and reproduction in any medium, provided the original work is properly cited.

\section{INTRODUCTION}

The peroxisome proliferator-activated receptor- $\gamma$ (PPAR- $\gamma$ ) is a ligand-inducible transcription factor that belongs to a large superfamily comprising the nuclear receptors for steroids, thyroid hormones, and retinoids. The PPAR- $\gamma$ and the two closely related PPAR- $\alpha$ and PPAR- $\delta$ (also known as $\beta$, NUC-1, or FAAR) are activated by naturally occurring fatty acids and act as sensors that regulate whole body metabolism in response to the dietary intake by controlling lipid and carbohydrate metabolism and lipid storage [1]. All three PPARs, once agonist-activated,form heterodimers with retinoic $\mathrm{X}$ receptors and regulate specific target gene transcription by binding to specific DNA regions (peroxisome proliferator response elements, PPREs) or by a mechanism independent of PPRE binding, termed transrepression, which begins to be unravelled [2].

Because of their role in the regulation of genes involved in lipid and carbohydrate metabolism, PPARs deeply affect lipid homeostasis and insulin sensitivity $[3,4]$. The serum glucose lowering activity of PPAR- $\gamma$ has lead to the development of specific PPAR- $\gamma$ agonists for the treatment of type-2 diabetes and the metabolic syndrome [5]. PPAR- $\gamma$ agonists such as thiazolidinediones (TZD), including pioglitazone (Actos) and rosiglitazone (Avandia), increase insulin sensitivity thereby improving glycaemic control, but also modify lipidemic profile and decrease blood pressure [6-9]. On the other hand, fibrates, which are PPAR- $\alpha$ agonists, are prevalently antilipidemic drugs, and therapeutic benefits of PPAR$\alpha$ and PPAR- $\gamma$ activations, which only are minimally overlapping, have generated interest in dual agonists that target both receptors, thus offering improved insulin sensitivity and lipidemic control in the same molecule $[10,11]$. This would provide a therapeutic tool against diabetes and the metabolic syndrome.

The three PPARs share a high homology, but differ for tissue distribution and ligand specificity. PPAR- $\alpha$ is mainly expressed in tissues with high catabolic rates of fatty acids, such as the liver, muscle, and heart, whereas PPAR- $\delta$ shows a much wider distribution. PPAR- $\gamma$ is highly expressed in 
adipose tissue, where it plays a central role in the regulation of adipocyte differentiation [12], and in cells of the immune system, including lymphocytes and macrophages. In peripheral monocytes, PPAR- $\gamma$ expression is induced during the process of extravasation from blood vessels into the tissues, and in the course of activation by pro-inflammatory stimuli, suggesting that PPAR- $\gamma$ is important for promoting monocyte-macrophage differentiation and activation and, thus, controlling inflammation [13-16]. As for macrophages of peripheral tissues, PPAR- $\gamma$ regulates the activation of microglial cells, the main macrophage population found in brain parenchyma, and increasing evidence indicates that PPAR- $\gamma$ might modulate brain inflammation and neurodegeneration [17] and be exploited as valuable therapeutic target in neurological diseases [18]. Indeed, brain inflammation is increasingly viewed as a target for treating neurological diseases, not only in classical infectious and immune-mediate disorders such as meningitis or multiple sclerosis, but also in stroke, trauma, and neurodegenerative diseases that were not originally considered to be inflammatory $[19,20]$.

In a similar way, inflammation could represent an important target to treat ocular diseases. In the study of ophthalmology, the classical subdivision of pathology textbooks in metabolic, inflammatory, hemodynamic, and degenerative disorders appears artificial and does not reflect the complexity of conditions, where inflammation, dysmetabolic and hemodynamic disorders, and neurodegeneration often conspire to the development of diseases. Paradigmatic example is diabetic retinopathy (DR), where a metabolic derangement (hyperglycemia) triggers a pathologic pathway, characterized initially by inflammation (leukostasis, enhanced retinal vascular permeability, Muller cell, and microglial activation), followed by microvasculature alterations and ischemia (proliferative DR), eventually leading to degeneration of neural retina and visual loss. To this complexity, a simplicity in the natural history may correspond and the course of different retinal diseases may at a certain stage converge toward a similar evolution. For example, pathologic neovascularization may be the same and ominous outcome of DR, age-related macular degeneration (AMD), and autoimmune uveitis, conditions that are very far from each other from the point of view of etiology.

In the present article, we will first briefly review the immune cells that participate to the ocular inflammation, mainly microglia, and the role of PPAR- $\gamma$ in controlling their functions. In a second part, we will consider three conditions, where inflammation has a relevant function, microglia is involved, and the role of PPARs has been taken into consideration: DR, AMD, and optic neuritis (ON).

\section{MICROGLIAL CELLS AND OTHER CELL POPULATIONS OF THE IMMUNE RESPOSE IN THE EYE.}

Glial cells are the primary participants in the formation of scars in response to retinal or ocular injury and diseases. In addition, under normal conditions, they carry out a variety of supportive functions for the neurons with which they are closely related. Glial cells include astrocytes, oligoden- drocytes, the retina-specific Muller-glial cells, and microglia, which are considered the main immune resident cells.

Retinal microglia, like their counterpart in the brain, belong to the myeloid lineage and their myeloid progenitors enter the nervous system primarily during embryonic and fetal periods of development. During embryogenesis, microglial precursors migrate to the retina before retinal vascularization and differentiate into ramified, quiescent microglia typical of adult healthy retina. A second population of phagocytes, which express macrophage markers, invades the retinal later through the developing vasculature and remains associated with the blood vessels (see below). In the adult retina, microglia are distributed through most of the retinal layers, including outer plexiform layer, outer nuclear layer, inner plexiform layer, ganglion cell layer, and nerve fiber layer. Engraftment experiments have shown that they display some proliferative capacity and have a slow turnover in respect of other macrophage populations [21]. Disturbances in the number or distribution of these cells disrupt the normal development of the eye and its related structures. Ritter and collaborators [22] have recently reported that myeloid progenitors migrate to vascular regions of the retina where they differentiate into microglia and facilitate the normalization of the vasculature, thus underlining a main role of microglial cells in promoting and maintaining retinal vasculature during development.

Microglia show particular capacity of interaction with retinal cells, supervising the immune environment (see [23] and references therein). As for microglia in the brain parenchyma, retinal microglial cells are immunocompetent cells, able to remove the debris created during normal eye development or degenerative conditions by phagocytosis and to mount an inflammatory and immune response against ocular injury, infection, and disease.

Under normal conditions, microglia are characterized by a downregulated phenotype when compared to other macrophage populations of peripheral tissues. The maintenance of microglia in this "inhibited" state is crucial for the regulation of the immune state of the retina, which has to maintain tissue homeostasis while preventing the destructive potential of inflammatory and immune response. The complexity of the several intraocular structures on which the correct vision is dependent renders the eye particularly vulnerable to the reactions of the immune system against invading pathogens or ocular injury. To prevent that a defensive reaction can transform into a threat to vision in itself, the eye is equipped with several regulatory mechanisms, which contribute to make the eye an "immune-privileged" site [24]. As recently described for the brain parenchyma [25], the immune privilege is not an absolute or an immutable state, but rather it is the result of the active interplay among specialized cellular elements and specific microenvironment characteristics, and it can be overcome in several instances. Among the main features that account for the ocular immune privilegeare is the presence of blood-ocular barriers (the bloodaqueous barrier and the blood-retinal barrier), which are physical barriers between the local blood vessels and most parts of the eye itself, and the peculiar characteristics of the resident immune cells, namely, microglia, which are largely dependent on the presence of immunomodulatory factors 
TABLE 1: Retinal pathologies characterized by microglial activation.

\begin{tabular}{lc}
\hline Pathology & References \\
\hline Diabetic retinopathy & {$[26-29]$} \\
Glaucomatous optic nerve degeneration & {$[30-33]$} \\
Human retinitis pigmentosa & {$[34]$} \\
Age-related macular degeneration & {$[34,35]$} \\
Retinal ischemia and reperfusion injury & {$[36,37]$} \\
Retinal degeneration & {$[14,20,38]$} \\
\hline
\end{tabular}

in the aqueous humor and on the cross-talk between microglia and retinal cells. Several "ligand-receptor-" type interactions between retinal cells and microglia contribute to maintaining microglia in a nonactivated state. Among these, the glycoprotein CD200, which in the retina is extensively expressed in neurons and endothelial cells, and the cognate ligand CD200L on microglia [39], and the neuronal chemokine fractalkine (or CX3CL1) and its microglial receptor CX3CR1 [40].

In spite of their apparent "dormant" state, resting microglia actively monitor the surrounding microenvironment with extremely motile processes and protrusions, entering in contact with other cellular elements and sensing alterations in the nearby environment, to which they rapidly react. Microglial activation comprises morphological changes, such as cellular hypertrophy, retraction of processes, and expression of surface markers, as well as functional changes, including proliferation, migration, phagocytosis, and production of bioactive molecules. Activated microglia have been described in several forms of retinal injury or disease (see Table 1), in which they are believed to play major roles, either protective or detrimental. Indeed, activated microglia can, on one side, remove the degenerating neurons and contribute to re-establish tissue integrity; on the other side, they can secrete proinflammatory cytokines such interleukin (IL)- $1 \beta$, IL-3, IL-6, tumour necrosis factor (TNF)- $\alpha$, and interferon (IFN)- $\gamma$, which can be toxic to neurons and photoreceptors $[41,42]$ or to other cellular targets such as oligodendrocytes $[43,44]$. In addition, several of these microglial products can up-regulate the expression of vascular cell adhesion molecules and chemokines [45-47], thus promoting the recruitment of lymphocytes and macrophages, and enhancing the immune-mediated tissue damage $[23,48]$. In this context, molecules that can enable the control of microglial activation represent valuable tools to counteract the detrimental effects of inflammation and immune response while fostering those necessary for healing.

In addition to microglia, other cell types contribute to the immune response in the eye. The perivascular macrophages reside outside the blood-ocular barrier, in the space that separates the endothelium of the retinal capillaries and retinal pigment epithelium (RPE). Because of their anatomical location, they escape the tight control to which retinal microglia are subjected and their morphology and immunophenotype are very similar to those of macrophages of peripheral tissues. In close proximity, but separate from perivascular macrophages are the pericytes, which are be- lieved to be essential as structural support in microcirculation. In addition, together with astrocytes and Muller glia, they are considered to play a major role in maintaining the inner blood-retinal barrier [49]. These cells, of mesodermal origin, are enclosed within the basal lamina on the abluminal surface of endothelial cells and contain contractile proteins. Pericytes have been shown to control vessel constriction and retinal blood flow [50], and are involved in several pathological conditions, including hypoxia, hypertension, and DR. Their activation, since the very early phases of disease, is thought contribute to the disruption of the bloodretinal barrier [51]. Finally, the RPE cells are important in ocular immune response and in maintaining the eye immune privilege. These cells form a monolayer between the neuroretina and the choroids and are the essential component of the outer blood-retinal barrier. One of the main characteristics of RPE cells is the presence of tight junctions at the apical side of their lateral membrane, which render the monolayer impermeable for macromolecules and limit access of blood components to the retina. In addition to several important supportive functions, including regulation of transport of nutrients to the photoreceptors, phagocytosis of damaged or old rod outer segments, and production of growth factors, RPE cells contribute to the immune and inflammatory response of the retina by expressing major histocompatibility complex (MHC) antigens, adhesion molecules, and a variety of cytokines, which may either promote or enhance immune responses or down-regulate them [52].

In addition to the cell types so far described, a novel population of dendritic cells has been recently reported in normal mouse retina, distinguishable by the cell types by the extent of specific surface antigens and anatomical tissue location [53].

\section{DIABETIC RETINOPATHY}

Diabetic retinopathy (DR) is one of the most serious complications of diabetes and the leading cause of blindness among working-age adults. DR symptoms are mostly due to the vascular alterations that affect the retina. The early events are increased blood flow and abnormal vessel permeability, due to the impairment of blood-retinal barrier. They are caused by hyperglycemia and the other metabolic consequences of excess glucose disposal. As the disease progresses, retinal vasculopathy develops, showing loss of pericytes, smooth muscle and endothelial cell death, and microaneurysm formation, resulting in areas of ischemia in the retina. At this stage, upregulation of proangiogenic factors in ischemic retina, such as vascular endothelial growth factor (VEGF), initiates a vicious circle of neovascularization (proliferative DR), characterized by enhanced vascular leakage and formation of new, weak, and prone-to-break blood vessels, which further deteriorates retinal perfusion, worsens ischemia and eventually leads to visual loss.

Although the pathogenetic cascade connecting these events is still unclear, evidence suggesting a role for inflammation in DR is accumulating, supporting the involvement of both chemical mediators and inflammatory cells in the pathogenesis of the disease [54]. Elevated levels of 
proinflammatory cytokines, such as IL- $1 \beta$, IL-6 and IL-8, and TNF- $\alpha$ and vascular cell adhesion molecule-1, have been found in the vitreous of patients with proliferative DR [5557]. Increased VEGF and IL-6 levels were detected in the aqueous humor of diabetic patients with macular edema [58]. TNF- $\alpha$ was found in epiretinal membranes of proliferative DR [59]. Data from experimental models are in line with these observations. In streptozotocin (STZ)-induced diabetic rats, changes in retinal blood vessel permeability, which characterizes the early phases of DR, are paralleled by increase in the level of the intercellular cell adhesion molecule-1 (ICAM-1), which facilitates the trafficking of leukocytes [60], and pro-inflammatory mediators, such as TNF- $\alpha$ and cyclooxygenase-2 (COX-2) $[61,62]$. In the same animal model, an increased level of IL- $1 \beta$ has been observed and put in relation to upregulated inducible nitric oxide synthase (iNOS) [63]. Mice deficient in the leukocyte adhesion molecules CD18 and ICAM-1 demonstrate significantly fewer adherent leukocytes in the retinal vasculature after induction of diabetes with STZ [54]. According to some authors, VEGF could be responsible for the initiation of the inflammatory cascade, as its administration in vivo was found to induce retinal ICAM1 and endothelial NOS (eNOS) expression [64, 65]. As far as inflammatory cells are concerned, microglia seem to be mostly involved. Microglial activation appears early in the course of DR, before the onset of overt neuronal cell death [62]. In STZ-induced diabetic rats, hypertrophic microglia were observed one month after the onset of diabetes [66], with significant increase also in cell number [67]. In mice with alloxan-induced diabetes, changes in microglial cell morphology were the first detectable cellular modifications, apparently preceding ganglion cell apoptosis and increase in blood barrier permeability [68]. Treatment of STZ-induced diabetic rats with minocycline, a semisynthetic tetracycline that counteracts microglial activation, besides decreasing the expression of proinflammatory cytokines, decreased caspase3 levels [62], suggesting a potential neuroprotective antiapoptotic effect of inhibition of microglial activation.

Considering the role of inflammation in the pathogenesis of DR, it has been suggested that PPAR- $\gamma$ ligands exert therapeutic effects also as modulators of inflammation, besides providing glycemic control [69]. In diabetic patients, PPAR- $\gamma$ agonists reduce several markers of inflammation, such as serum levels of C-reactive protein, IL-6, monocyte chemoattractant protein-1 (MCP-1), plasminogen activator inhibitor-1, soluble CD40 ligand, and matrix metalloproteinase-9 [70-75]. In addition, they have been shown to induce the suppression of activated $\mathrm{NF} \kappa \mathrm{B}$ and decrease ROS generation in blood mononuclear cells [70, 73].

Modulation of the inflammatory process has also been studied in DR in in vivo models. In streptozotocin-induced $\mathrm{DR}$, rosiglitazone was shown to inhibit both retinal leukostasis and retinal leakage [76]. The effect was not accompanied by downregulation of proinflammatory cytokines, such as TNF- $\alpha$, although the adhesion molecule ICAM was found reduced. Nitric Oxide (NO) of endothelial origin regulates ocular blood flow. In the endothelial dysfunction, which characterizes the early stages of DR, a reduction in the bioavailability of NO may contribute to impairment of oc- ular hemodynamics [77]. In bovine aortic endothelial cells, troglitazone increased NO production in a dose- and timedependent manner with no modifications in eNOS expression [78]. A study focused on NO production in pericytes showed that PPAR- $\gamma$ is constitutively expressed in retinal pericytes and that troglitazone increases NO production and iNOS expression in a PPAR- $\gamma$-dependent manner, an effect which is opposite to what observed in cultured microglia $[79,80]$. This study suggests that PPAR- $\gamma$ agonists, in addition to improving insulin sensitivity, might also improve retinal microcirculation in early DR [81]. However, NO is a double-edged sword. Overproduction of NO by neuronal NOS is supposed to contribute to retinal injury in ischemia $[82,83]$. Thus, although in DR early phase an increase in NO may contribute to the improvement of retinal microcirculation, in proliferative DR a beneficial effect is doubtful. A further reason of concern is represented by TZD effects on VEGF. Several in vivo and in vitro studies have reported increased expression of VEGF in response to PPAR- $\gamma$ ligands. TZDs have been found to upregulate VEGF in human vascular muscle cells [84], in 3T3-L1 adipocytes [85], in cultured cardiac myofibroblasts [86]. In bovine aortic endothelial cells treated with troglitazone, $\mathrm{NO}$ increase was accompanied by upregulation of VEGF and its receptor, KDR/Flk-1 [78]. Administration of pioglitazone [87] and troglitazone [85] also significantly increased plasma VEGF levels in diabetic patients. Considering the role played by VEGF in the development and progression of DR, caution has been suggested in the use of PPAR- $\gamma$ ligands in patients with advanced disease $[85,87]$. However, in partial disagreement with the results above reported, antiangiogenic properties of PPAR agonists have been shown both in in vitro and in vivo models $[35,88-$ 90]. In neonatal mice, where ischemia was used as a model of retinal neovascularization, intravitreous injection of rosiglitazone or troglitazone inhibited development of new retinal vessels [91]. In the same study, TZDs have been found to inhibit retinal endothelial cell proliferation, migration, and tube formation in response to VEGF treatment [91]. Further studies are therefore required to clarify the issue.

\section{AGE-RELATED MACULAR DEGENERATION}

Age-related macular degeneration (AMD) is the leading cause of vision loss in the elderly in the western world. It is characterized by degeneration of the macula, the central area of the retina with the highest concentration of cone photoreceptors, responsible for visual acuity and color vision. Histopathologically, the early phase of AMD is characterized by formation of drusen, deposits of lipid and cellular debris that are found between the RPE cells and Bruch's membrane, possibly as a result of RPE degeneration or, as recently proposed [92], microglial infiltration and transformation in foam cells. As the disease proceeds, photoreceptor degeneration and, in the most aggressive cases, choroidal neovascularization (CNV) intervene, with growth of new blood vessels from the choroids into the subretinal space. Two major clinical phenotypes of AMD are recognized: nonexudative (dry type), and exudative (wet type). The latter more frequently develops into CNV. 
AMD is a complex, multifactorial disease and both genetic and environmental factors may contribute at some level. In the pathogenesis of the disease, both altered angiogenesis and inflammation play a role. The study of pathologic angiogenesis in the retina has focused on two main factors: the angiogenic VEGF $[93,94]$ and the antiangiogenic PEDF [94-96], although a number of other factors are implicated(for a review, see [97]). It is widely agreed that in $\mathrm{CNV}$ an imbalance between angiogenic and anti-angiogenic factors takes place, but what disrupts this delicate equilibrium is still unclear. Several lines of evidence point to inflammation as a pathogenetic mechanism. Many risk factors for AMD are related to inflammation, including environmental factors, such as smoking and low intake of omega-3 fatty acid $[98,99]$, and genetic factors, such as polymorphisms of complement factor $\mathrm{H}$ [100-102] and the chemokine receptor CX3CR, which is expressed by microglia and mediates migration and adhesion in response to its ligand fractalkine or CX3CL1 [103]. Increased serum levels of IL-6 and C-reactive protein have been found to be related with progression of AMD [104]. More recently, IL-6 receptor neutralization has shown to lead to decrease in the expression of inflammatory mediators, such as the chemokine MCP-1, the adhesion molecule ICAM-1, and VEGF, and to reduce macrophage infiltration into $\mathrm{CNV}$ in in vivo model of the disease [105]. Inflammatory mediators, such as macrophage chemoattractants and activated complement components, especially C3a and $\mathrm{C} 5 \mathrm{a}$, are also found in drusen samples from AMD patients [106-108]. A role for complement in the development of the disease has been suggested [34]. In line with this hypothesis, it has been observed that genetic ablation of receptors for C3a or C5a reduced VEGF expression, leukocyte recruitment, and CNV [109].

Activation of microglia and infiltration of macrophages have been reported in the human AMD as well as in experimental CNV [110-112]. In transgenic mice lacking CX3CR1, microglia migrate defectively and accumulate in the subretinal space, evoking morphological and pathological features similar to those observed in human AMD. In addition, laser-induced CNV was exacerbated in these mice [92]. A controversy exists regarding the origin of activated retinal mononuclear phagocytes, that is, whether they are resident microglia $[113,114]$ or bloodderived bone marrow macrophages $[46,115]$. In support of the latter hypothesis, it should be noted that systemic depletion of macrophages using clodronate-filled liposomes blocked neovascularization [116, 117]. However, the role of macrophages is still debated, since some studies suggest an antiangiogenic role for macrophages. For example, mice lacking CC chemokine ligand 2 (CCL2) or its receptor, both involved in chemoattraction of macrophages and/or microglia, show drusen-like deposits and CNV, suggesting that macrophage recruitment may protect against AMD [118]. In addition, mice lacking IL-10, an anti-inflammatory cytokine known to control macrophage/microglia functions, had significantly reduced neovascularization and increased macrophage infiltrates compared to wild type, in a laserinduced model of CNV. In these experiments, prevention of macrophage entry into the eye promoted neovascularization while direct injection of macrophages significantly inhibited CNV.

As mentioned earlier, beside mononuclear phagocytic cells, RPE cells have also a role in the inflammatory and angiogenetic process, as a major source of VEGF and PEDF. In addition, there is a cross-talk between RPE and macrophages. It has been shown that macrophages in CNV are immunopositive for VEGF, TNF- $\alpha$, and IL-1 $\beta$ [119]. The latter factors can induce the secretion of IL- 8 and MCP- 1 in RPE cells in vitro $[120,121]$. MCP-1 is, in turn, involved in the recruitment of macrophages [122], thus closing the circle. Indeed, in surgically excised CNV specimens, RPE was found to express VEGF and MCP-1 and macrophages were immunolabeled for VEGF [123].

The interest in the role of PPARs in AMD has been mainly focused on their activities as modulators of angiogenesis. PPAR agonists have shown antiangiogenic properties both in in vitro and in vivo models $[35,88,89]$. It has been shown that choroidal ECs and RPE cells express PPAR- $\gamma$ and that PPAR- $\gamma$ ligands inhibit their response to VEGF, without apparent toxicity to the adjacent retina, in a laser-induced model of CNV [90]. Decrease in angiogenesis apparently takes place by inhibition of VEGF, since PPAR- $\alpha$ agonists are found to inhibit endothelial VEGFR2 expression [124]. An opposite role has been recently described for $\operatorname{PPAR} \delta$, which induced endothelial proliferation and angiogenesis in vitro, through a VEGF-dependent mechanism [125]. The natural ligand 15 -deoxy- $\Delta^{12,14}$-prostaglandin $\mathrm{J}_{2}\left(15 \mathrm{~d}-\mathrm{PGJ}_{2}\right)$ was found to protect a human RPE cell line from oxidative stress by elevating GSH and enhancing MAPK activation, but such activity was independent of its PPAR- $\gamma$ binding activity [126]. The roles of infiltrating macrophages and/or resident microglia in the pathogenesis of AMD open the possibility that PPAR- $\gamma$ agonists may ameliorate the course of the disease also through the down-regulation of several proinflammatory functions of these cells [8] and reference therein, including TNF- $\alpha$ and iNOS, and MHC-II expression.

However, possible beneficial effects of PPAR- $\gamma$ agonists in the treatment of ocular inflammation and, particularly, of AMD need to be further verified. It is important to keep in mind that PPAR- $\gamma$ is involved in the differentiation of macrophages to foaming cells and PPAR- $\gamma$ ligands can induce expression of adipocyte lipid binding protein (ALBP/aP2), a gene that is highly expressed in vivo in macrophage/foam cells of human atherosclerotic plaques [127]. Moreover, activation of PPAR- $\gamma$ has been shown to reduce CCR2 expression in monocytes and their chemotaxis in response to MCP1 [128]. These PPAR $-\gamma$ mediated activities are of particular interest in the view of the recent finding by Combadière et al. [92], suggesting that subretinal microglial foam cells might be the origin of drusen-like deposits and that accumulation of microglia in the subretinal space may be a driving force in the pathogenesis of AMD.

\section{OPTIC NEURITIS AND RELATED DISORDERS}

Optic neuritis $(\mathrm{ON})$, an inflammatory, demyelinating disease of the optic nerve, may be the initial symptom of multiple sclerosis (MS) or appear in the course of the disease. 
TABLE 2: PPAR agonists and EAE.

\begin{tabular}{|c|c|c|c|}
\hline Agonists & Biological activity & Receptor & References \\
\hline Troglitazone & $\begin{array}{l}\text { Amelioration of clinical symptoms. Reduced expression } \\
\text { of proinflammatory cytokines, IL1 } \beta \text { and TNF- } \alpha\end{array}$ & PPAR- $\gamma$ & [129] \\
\hline Ciglitazone, $15 \mathrm{~d}-\mathrm{PGJ}_{2}$ & $\begin{array}{l}\text { Decrease of severity and duration of clinical paralysis. } \\
\text { Decrease of CNS inflammation and demyelination. De- } \\
\text { crease of IL-12 production }\end{array}$ & PPAR- $\gamma$ & {$[130]$} \\
\hline $15 \mathrm{~d}-\mathrm{PGJ} \mathrm{J}_{2}$ & $\begin{array}{l}\text { Delay in the onset and decrease in the severity of disease. } \\
\text { Reduction of Con A- and MBP Ac1-11-reactive, IFN- } \alpha \text { - } \\
\text { and IL- } 4 \text {-secreting cells }\end{array}$ & PPAR- $\gamma$ & {$[131]$} \\
\hline Pioglitazone & $\begin{array}{l}\text { Decreased mRNA levels of iNOS and the chemokines } \\
\text { MIP1 and RANTES in the central nervous system }\end{array}$ & PPAR- $\gamma$ & {$[132]$} \\
\hline Gemfibrozil and fenofibrate & $\begin{array}{l}\text { Dose-dependent suppression of lymphocyte prolifera- } \\
\text { tion. Promotion of IL- } 4 \text { production and inhibition of } \\
\text { IFN- } \gamma \text { production }\end{array}$ & PPAR- $\alpha$ & {$[133]$} \\
\hline GW0742 & $\begin{array}{l}\text { Improvement of clinical recovery. Reduction of glial } \\
\text { activation }\end{array}$ & PPAR- $\delta$ & {$[134]$} \\
\hline Ciglitazone, $15 \mathrm{~d}-\mathrm{PG} \mathrm{J}_{2}$ & $\begin{array}{l}\text { Amelioration of clinical and pathological symptoms. In- } \\
\text { hibition of neural antigen-specific } \mathrm{T} \text { cell proliferation }\end{array}$ & PPAR- $\gamma$ & {$[135]$} \\
\hline Gemfibroil & $\begin{array}{l}\text { Reduction of incidence and clinical signs. Inhibition of } \\
\text { the infiltration of inflammatory cells into the CNS. Re- } \\
\text { duced expression of proinflammatory molecules such as } \\
\text { iNOS, IL-1, IL-6, and TNF- } \alpha\end{array}$ & no PPAR- $\gamma$ & {$[136]$} \\
\hline Pioglitazone & $\begin{array}{l}\text { Prevention of relapse episodes and reduction of mean } \\
\text { clinical scores during the treatment period. Decrease of } \\
\text { IFN- } \gamma \text { levels }\end{array}$ & PPAR- $\gamma$ & {$[137]$} \\
\hline
\end{tabular}

In any event, nearly half of MS patients develop ON during the course of the disease. An idiopathic demyelinating disorder of the optic nerve also occurs as NeuroMyelitis Optica (NMO) or Devic's disease, which is characterized by the coexistence of usually bilateral and severe optic neuritis with spinal cord involvement and the presence of a highly specific serum autoantibody marker (NMO-IgG), recognizing the transmembrane channel Aquaporin 4 [138, 139]. The boundaries between NMO and MS are, however, rather imprecise, from both the clinical and pathologic points of view and it is still a matter of controversy whether NMO should be considered a variant of MS or a separate entity $[139,140]$.

Considering their role in inflammation, the possible therapeutic efficacy of PPAR- $\gamma$ agonists has been studied in experimental autoimmune encephalomyelitis (EAE), an animal model of the disease where the autoimmune reaction against myelin is induced in animals by active sensitization with myelin components. Although several criticisms have been moved towards this model, EAE still provides a valuable tool for improving our understanding on the pathogenesis and treatment of MS. EAE is also considered a model relevant to the study of demyelinated diseases of the optic nerve $[141,142]$. An additional animal model is represented by $\mathrm{T}$ cell receptor transgenic mice specific for myelin oligodendrocyte glycoprotein (MOG). These mice develop isolated optic neuritis either spontaneously or after sensitization with suboptimal doses of MOG [143]. Therapeutic efficacy of PPAR- $\gamma$ ligands has been demonstrated in terms of suppression or amelioration of clinical symptoms and decrease of inflammatory signs (see Table 2). Although the anti- inflammatory activities of PPAR- $\gamma$ agonists are complex and multifaceted, evidence has been provided suggesting a direct action of PPAR- $\gamma$ agonists on microglia/mononuclear phagocytic cells. Indeed, taking part in both innate and adaptive immune responses, microglia and mononuclear phagocytes are deeply implicated in the complex inflammatory cascade associated with MS. Their role has been recently and extensively reviewed $[144,145]$. The PPAR- $\gamma$ natural agonist $15 \mathrm{~d}-\mathrm{PGJ}_{2}$ [146] and the PPAR- $\alpha$ agonist gemfibrozil [133] were found to significantly reduce macrophage infiltration in the lesions. A decreased number of IL- $1 \beta$-positive cells were found in EAE brain of mice treated with GW0742 and a PPAR- $\delta$ agonist and this observation was considered indicative of a reduction of glial activation [134]. PPAR- $\gamma$ inhibition of microglial cell activation is also supported by in vitro experiments [8, 79, 80, 147-152].

Notwithstanding the amount of data regarding a therapeutic activity of PPAR agonists in EAE, clinical studies are lacking and report on their clinical use in MS or ON is still anecdotical [153]. Clinical trials are however in course with pioglitazone and rosiglitazone.

\section{CONCLUSIONS}

The promising results obtained in experimental models of ocular diseases and the recent advancements in the knowledge of the pathogenic mechanisms driving ocular damage and vision loss strongly point to PPAR- $\gamma$ as a valuable target to control inflammation and treat invalidating diseases such as DR, AMD, and ON. Given the complexity of the 
phenomena that can be influenced by PPAR- $\gamma$ activation, involving not only inflammation but also retinal microcirculation, neovascularization, and transformation of activated microglia in foam cells contributing to drusen-like deposits, further studies are mandatory for a correct evaluation of pro and cons of using PPAR- $\gamma$ agonists in ocular disease treatment. The PPAR- $\gamma$ agonists could also find other important applications in controlling the adverse effects of inflammation that can put at risk the eye integrity and the correct vision. As an example, some of the adverse reactions described after liquid artificial vitreous replacement use in vitreoretinal surgery are a consequence of inflammatory reaction and activation of mononuclear phagocytic cells [154], suggesting that the use of PPAR- $\gamma$ agonists could be very advantageous in controlling the inflammatory response to biomaterials.

\section{REFERENCES}

[1] B. Desvergne and W. Wahli, "Peroxisome proliferatoractivated receptors: nuclear control of metabolism," Endocrine Reviews, vol. 20, no. 5, pp. 649-688, 1999.

[2] M. Ricote and C. K. Glass, "PPARs and molecular mechanisms of transrepression," Biochimica et Biophysica Acta, vol. 1771, no. 8, pp. 926-935, 2007.

[3] P. Escher and W. Wahli, "Peroxisome proliferator-activated receptors: insight into multiple cellular functions," Mutation Research, vol. 448, no. 2, pp. 121-138, 2000.

[4] M. Stumvoll and H.-U. Häring, "Glitazones: clinical effects and molecular mechanisms," Annals of Medicine, vol. 34, no. 3, pp. 217-224, 2002.

[5] P. Gervois, J.-C. Fruchart, and B. Staels, "Drug insight: mechanisms of action and therapeutic applications for agonists of peroxisome proliferator-activated receptors," Nature Clinical Practice Endocrinology \& Metabolism, vol. 3, no. 2, pp. 145156, 2007.

[6] H. Yki-Järvinen, “Thiazolidinediones,” New England Journal of Medicine, vol. 351, no. 11, pp. 1106-1118, 2004.

[7] P. Delerive, J.-C. Fruchart, and B. Staels, "Peroxisome proliferator-activated receptors in inflammation control," Journal of Endocrinology, vol. 169, no. 3, pp. 453-459, 2001.

[8] P. Gerber, G. Lübben, S. Heusler, and A. Dodo, "Effects of pioglitazone on metabolic control and blood pressure: a randomised study in patients with type 2 diabetes mellitus," Current Medical Research and Opinion, vol. 19, no. 6, pp. 532539, 2003.

[9] P. A. Sarafidis, A. N. Lasaridis, P. M. Nilsson, et al., "Ambulatory blood pressure reduction after rosiglitazone treatment in patients with type 2 diabetes and hypertension correlates with insulin sensitivity increase," Journal of Hypertension, vol. 22, no. 9, pp. 1769-1777, 2004.

[10] B. R. Henke, "Peroxisome proliferator-activated receptor $\alpha / \gamma$ dual agonists for the treatment of type 2 diabetes," Journal of Medicinal Chemistry, vol. 47, no. 17, pp. 4118-4127, 2004.

[11] D. M. Kendall, C. J. Rubin, P. Mohideen, et al., "Improvement of glycemic control, triglycerides, and HDL cholesterol levels with muraglitazar, a dual $(\alpha / \gamma)$ peroxisome proliferatoractivated receptor activator, in patients with type 2 diabetes inadequately controlled with metformin monotherapy: a double-blind, randomized, pioglitazone-comparative study," Diabetes Care, vol. 29, no. 5, pp. 1016-1023, 2006.
[12] T. M. Willson, M. H. Lambert, and S. A. Kliewer, "Peroxisome proliferator-activated receptor $\gamma$ and metabolic disease," Annual Review of Biochemistry, vol. 70, pp. 341-367, 2001.

[13] R. A. Daynes and D. C. Jones, "Emerging roles of PPARs in inflammation and immunity," Nature Reviews Immunology, vol. 2, no. 10, pp. 748-759, 2002.

[14] M. Ricote, J. Huang, L. Fajas, et al., "Expression of the peroxisome proliferator-activated receptor $\gamma(\operatorname{PPAR} \gamma)$ in human atherosclerosis and regulation in macrophages by colony stimulating factors and oxidized low density lipoprotein," Proceedings of the National Academy of Sciences of the United States of America, vol. 95, no. 13, pp. 7614-7619, 1998.

[15] M. Ricote, A. C. Li, T. M. Willsons, C. J. Kelly, and C. K. Glass, "The peroxisome proliferator-activated receptor- $\gamma$ is a negative regulator of macrophage activation," Nature, vol. 391, no. 6662, pp. 79-82, 1998.

[16] P. Tontonoz, L. Nagy, J. G. A. Alvarez, V. A. Thomazy, and R. M. Evans, "PPAR $\gamma$ promotes monocyte/macrophage differentiation and uptake of oxidized LDL," Cell, vol. 93, no. 2, pp. 241-252, 1998.

[17] A. Bernando and L. Minghetti, "PPAR- $\gamma$ agonists as regulators of microglial activation and brain inflammation," Current Pharmaceutical Design, vol. 12, no. 1, pp. 93-109, 2006.

[18] M. T. Heneka, G. E. Landreth, and M. Hüll, "Drug insight: effects mediated by peroxisome proliferator-activated receptor- $\gamma$ in CNS disorders," Nature Clinical Practice Neurology, vol. 3, no. 9, pp. 496-504, 2007.

[19] M. M. Esiri, "The interplay between inflammation and neurodegeneration in CNS disease," Journal of Neuroimmunology, vol. 184, no. 1-2, pp. 4-16, 2007.

[20] L. Minghetti, "Role of inflammation in neurodegenerative diseases," Current Opinion in Neurology, vol. 18, no. 3, pp. 315-321, 2005.

[21] H. Xu, M. Chen, E. J. Mayer, J. V. Forrester, and A. D. Dick, "Turnover of resident retinal microglia in the normal adult mouse," GLIA, vol. 55, no. 11, pp. 1189-1198, 2007.

[22] M. R. Ritter, E. Banin, S. K. Moreno, E. Aguilar, M. I. Dorrell, and M. Friedlander, "Myeloid progenitors differentiate into microglia and promote vascular repair in a model of ischemic retinopathy," Journal of Clinical Investigation, vol. 116, no. 12, pp. 3266-3276, 2006.

[23] T. Langmann, "Microglia activation in retinal degeneration," Journal of Leukocyte Biology, vol. 81, no. 6, pp. 1345-1351, 2007.

[24] J. W. Streilein, "Ocular immune privilege: the eye takes a dim but practical view of immunity and inflammation," Journal of Leukocyte Biology, vol. 74, no. 2, pp. 179-185, 2003.

[25] I. Galea, I. Bechmann, and V. H. Perry, "What is immune privilege (not)?" Trends in Immunology, vol. 28, no. 1, pp. 1218, 2007.

[26] L. Chen, P. Yang, and A. Kijlstra, "Distribution, markers, and functions of retinal microglia," Ocular Immunology \& Inflammation, vol. 10, no. 1, pp. 27-39, 2002.

[27] K. C. Silva, C. C. Pinto, S. K. Biswas, J. B. Lopes de Faria, and J. M. Lopes de Faria, "Hypertension increases retinal inflammation in experimental diabetes: a possible mechanism for aggravation of diabetic retinopathy by hypertension," Current Eye Research, vol. 32, no. 6, pp. 533-541, 2007.

[28] K. C. Silva, C. C. Pinto, S. K. Biswas, D. S. Souza, J. B. Lopes de Faria, and J. M. Lopes de Faria, "Prevention of 
hypertension abrogates early inflammatory events in the retina of diabetic hypertensive rats," Experimental Eye Research, vol. 85, no. 1, pp. 123-129, 2007.

[29] A. L. Wang, A. C. H. Yu, Q. H. He, X. Zhu, and M. O. M. Tso, "AGEs mediated expression and secretion of TNF $\alpha$ in rat retinal microglia," Experimental Eye Research, vol. 84, no. 5, pp. 905-913, 2007.

[30] L. Yuan and A. H. Neufeld, "Tumor necrosis factor- $\alpha$ : a potentially neurodestructive cytokine produced by glia in the human glaucomatous optic nerve head," GLIA, vol. 32, no. 1, pp. 42-50, 2000.

[31] R. Naskar, M. Wissing, and S. Thanos, "Detection of early neuron degeneration and accompanying microglial responses in the retina of a rat model of glaucoma," Investigative Ophthalmology \& Visual Science, vol. 43, no. 9, pp. 2962 2968, 2002.

[32] E. C. Johnson, L. Jia, W. O. Cepurna, T. A. Doser, and J. C. Morrison, "Global changes in optic nerve head gene expression after exposure to elevated intraocular pressure in a rat glaucoma model," Investigative Ophthalmology \& Visual Science, vol. 48, no. 7, pp. 3161-3177, 2007.

[33] D. M. Inman and P. J. Horner, "Reactive nonproliferative gliosis predominates in a chronic mouse model of glaucoma," GLIA, vol. 55, no. 9, pp. 942-953, 2007.

[34] L. A. Donoso, D. Kim, A. Frost, A. Callahan, and G. S. Hageman, "The role of inflammation in the pathogenesis of age-related macular degeneration," Survey of Ophthalmology, vol. 51, no. 2, pp. 137-152, 2006.

[35] X. Xin, S. Yang, J. Kowalski, and M. E. Gerritsen, "Peroxisome proliferator-activated receptor $\gamma$ ligands are potent inhibitors of angiogenesis in vitro and in vivo," Journal of Biological Chemistry, vol. 274, no. 13, pp. 9116-9121, 1999.

[36] O. Uckermann, S. Uhlmann, T. Pannicke, et al., "Ischemiareperfusion causes exudative detachment of the rabbit retina," Investigative Ophthalmology \& Visual Science, vol. 46, no. 7, pp. 2592-2600, 2005.

[37] C. Zhang, T. T. Lam, and M. O. M. Tso, "Heterogeneous populations of microglia/macrophages in the retina and their activation after retinal ischemia and reperfusion injury," Experimental Eye Research, vol. 81, no. 6, pp. 700-709, 2005.

[38] C. Zhang, J.-K. Shen, T. T. Lam, et al., "Activation of microglia and chemokines in light-induced retinal degeneration," Molecular Vision, vol. 11, pp. 887-895, 2005.

[39] A. D. Dick, D. Carter, M. Robertson, et al., "Control of myeloid activity during retinal inflammation," Journal of Leukocyte Biology, vol. 74, no. 2, pp. 161-166, 2003.

[40] A. E. Cardona, E. P. Pioro, M. E. Sasse, et al., "Control of microglial neurotoxicity by the fractalkine receptor," Nature Neuroscience, vol. 9, no. 7, pp. 917-924, 2006.

[41] D. T. Walsh, L. Bresciani, D. Saunders, et al., "Amyloid $\beta$ peptide causes chronic glial cell activation and neurodegeneration after intravitreal injection," Neuropathology and Applied Neurobiology, vol. 31, no. 5, pp. 491-502, 2005.

[42] H.-Y. Zeng, X.-A. Zhu, C. Zhang, L.-P. Yang, L.-M. Wu, and M. O. M. Tso, "Identification of sequential events and factors associated with microglial activation, migration, and cytotoxicity in retinal degeneration in $r d$ mice," Investigative Ophthalmology \& Visual Science, vol. 46, no. 8, pp. 2992-2999, 2005.

[43] L. Gao, W. Macklin, J. Gerson, and R. H. Miller, "Intrinsic and extrinsic inhibition of oligodendrocyte development by rat retina," Developmental Biology, vol. 290, no. 2, pp. 277286, 2006 .
[44] T. Nakazawa, C. Nakazawa, A. Matsubara, et al., "Tumor necrosis factor- $\alpha$ mediates oligodendrocyte death and delayed retinal ganglion cell loss in a mouse model of glaucoma," Journal of Neuroscience, vol. 26, no. 49, pp. 12633 12641, 2006.

[45] M. C. Madigan, P. L. Penfold, N. J. C. King, F. A. Billson, and R. M. Conway, "Immunoglobulin superfamily expression in primary retinoblastoma and retinoblastoma cell lines," Oncology Research, vol. 13, no. 2, pp. 103-111, 2002.

[46] A. Caicedo, D. G. Espinosa-Heidmann, Y. Piña, E. P. Hernandez, and S. W. Cousins, "Blood-derived macrophages infiltrate the retina and activate Muller glial cells under experimental choroidal neovascularization," Experimental Eye Research, vol. 81, no. 1, pp. 38-47, 2005.

[47] T. Nakazawa, T. Hisatomi, C. Nakazawa, et al., "Monocyte chemoattractant protein 1 mediates retinal detachmentinduced photoreceptor apoptosis," Proceedings of the $\mathrm{Na}$ tional Academy of Sciences of the United States of America, vol. 104, no. 7, pp. 2425-2430, 2007.

[48] M. H. Davies, J. P. Eubanks, and M. R. Powers, "Microglia and macrophages are increased in response to ischemiainduced retinopathy in the mouse retina," Molecular Vision, vol. 12, pp. 467-477, 2006.

[49] J. H. Kim, J. H. Kim, J. A. Park, et al., "Blood-neural barrier: intercellular communication at glio-vascular interface," Journal of Biochemistry and Molecular Biology, vol. 39, no. 4, pp. 339-345, 2006.

[50] C. M. Peppiatt, C. Howarth, P. Mobbs, and D. Attwell, "Bidirectional control of CNS capillary diameter by pericytes," $\mathrm{Na}$ ture, vol. 443, no. 7112, pp. 700-704, 2006.

[51] G. J. Guillemin and B. J. Brew, "Microglia, macrophages, perivascular macrophages, and pericytes: a review of function and identification," Journal of Leukocyte Biology, vol. 75, no. 3, pp. 388-397, 2004.

[52] M. Holtkamp, R. Zschenderlein, W. Brück, and J. R. Weber, "Chronic inflammatory demyelinating polyradiculoneuropathy with histologically proven optic neuritis," Acta Neuropathologica, vol. 101, no. 5, pp. 529-531, 2001.

[53] S. Xu, P. D. Witmer, S. Lumayag, B. Kovacs, and D. Valle, "MicroRNA (miRNA) transcriptome of mouse retina and identification of a sensory organ-specific miRNA cluster," Journal of Biological Chemistry, vol. 282, no. 34, pp. 25053-25066, 2007.

[54] A. M. Joussen, V. Poulaki, M. L. Le, et al., "A central role for inflammation in the pathogenesis of diabetic retinopathy," The FASEB Journal, vol. 18, no. 12, pp. 1450-1452, 2004.

[55] A. M. Abu el Asrar, D. Maimone, P. H. Morse, S. Gregory, and A. T. Reder, "Cytokines in the vitreous of patients with proliferative diabetic retinopathy," American Journal of Ophthalmology, vol. 114, no. 6, pp. 731-736, 1992.

[56] G. A. Limb, J. Hickman-Casey, R. D. Hollifield, and A. H. Chignell, "Vascular adhesion molecules in vitreous from eyes with proliferative diabetic retinopathy," Investigative Ophthalmology \& Visual Science, vol. 40, no. 10, pp. 2453-2457, 1999.

[57] T. Yuuki, T. Kanda, Y. Kimura, et al., "Inflammatory cytokines in vitreous fluid and serum of patients with diabetic vitreoretinopathy," Journal of Diabetes and Its Complications, vol. 15, no. 5, pp. 257-259, 2001.

[58] H. Funatsu, H. Yamashita, H. Noma, T. Mimura, T. Yamashita, and S. Hori, "Increased levels of vascular endothelial growth factor and interleukin- 6 in the aqueous humor of diabetics with macular edema," American Journal of Ophthalmology, vol. 133, no. 1, pp. 70-77, 2002. 
[59] D. Armstrong, A. J. Augustin, R. Spengler, et al., "Detection of vascular endothelial growth factor and tumor necrosis factor $\alpha$ in epiretinal membranes of proliferative diabetic retinopathy, proliferative vitreoretinopathy and macular pucker," Ophthalmologica, vol. 212, no. 6, pp. 410-414, 1998.

[60] K. Miyamoto, S. Khosrof, S.-E. Bursell, et al., "Prevention of leukostasis and vascular leakage in streptozotocin-induced diabetic retinopathy via intercellular adhesion molecule-1 inhibition," Proceedings of the National Academy of Sciences of the United States of America, vol. 96, no. 19, pp. 10836-10841, 1999.

[61] A. M. Joussen, T. Murata, A. Tsujikawa, B. Kirchhof, S.-E. Bursell, and A. P. Adamis, "Leukocyte-mediated endothelial cell injury and death in the diabetic retina," American Journal of Pathology, vol. 158, no. 1, pp. 147-152, 2001.

[62] J. K. Krady, A. Basu, C. M. Allen, et al., "Minocycline reduces proinflammatory cytokine expression, microglial activation, and caspase- 3 activation in a rodent model of diabetic retinopathy," Diabetes, vol. 54, no. 5, pp. 1559-1565, 2005.

[63] A. Carmo, J. G. Cunha-Vaz, A. P. Carvalho, and M. C. Lopes, "L-arginine transport in retinas from streptozotocin diabetic rats: correlation with the level of IL-1 $\beta$ and NO synthase activity," Vision Research, vol. 39, no. 23, pp. 3817-3823, 1999.

[64] M. Lu, V. L. Perez, N. Ma, et al., "VEGF increases retinal vascular ICAM-1 expression in vivo," Investigative Ophthalmology \& Visual Science, vol. 40, no. 8, pp. 1808-1812, 1999.

[65] A. M. Joussen, V. Poulaki, N. Mitsiades, et al., "Nonsteroidal anti-inflammatory drugs prevent early diabetic retinopathy via TNF- $\alpha$ suppression," The FASEB Journal, vol. 16, no. 3, pp. 438-440, 2002.

[66] X.-X. Zeng, Y.-K. Ng, and E.-A. Ling, "Neuronal and microglial response in the retina of streptozotocin-induced diabetic rats," Visual Neuroscience, vol. 17, no. 3, pp. 463-471, 2000.

[67] E. Rungger-Brändle, A. A. Dosso, and P. M. Leuenberger, "Glial reactivity, an early feature of diabetic retinopathy," Investigative Ophthalmology \& Visual Science, vol. 41, no. 7, pp. 1971-1980, 2000.

[68] D. Gaucher, J.-A. Chiappore, M. Pâques, et al., "Microglial changes occur without neural cell death in diabetic retinopathy," Vision Research, vol. 47, no. 5, pp. 612-623, 2007.

[69] P. Libby and J. Plutzky, "Inflammation in diabetes mellitus: role of peroxisome proliferator-activated receptor- $\alpha$ and peroxisome proliferator-activated receptor- $\gamma$ agonists," American Journal of Cardiology, vol. 99, no. 4, supplement 1, pp. 27-40, 2007.

[70] A. Aljada, R. Garg, H. Ghanim, et al., "Nuclear factor- $\kappa$ B suppressive and inhibitor $-\kappa \mathrm{B}$ stimulatory effects of troglitazone in obese patients with type 2 diabetes: evidence of an antiinflammatory action?" Journal of Clinical Endocrinology \& Metabolism, vol. 86, no. 7, pp. 3250-3256, 2001.

[71] S. M. Haffner, A. S. Greenberg, W. M. Weston, H. Chen, K. Williams, and M. I. Freed, "Effect of rosiglitazone treatment on nontraditional markers of cardiovascular disease in patients with type 2 diabetes mellitus," Circulation, vol. 106, no. 6, pp. 679-684, 2002.

[72] N. Marx, A. Imhof, J. Froehlich, et al., "Effect of rosiglitazone treatment on soluble CD40L in patients with type 2 diabetes and coronary artery disease," Circulation, vol. 107, no. 15, pp. 1954-1957, 2003.

[73] P. Mohanty, A. Aljada, H. Ghanim, et al., "Evidence for a potent antiinflammatory effect of rosiglitazone," Journal of
Clinical Endocrinology \& Metabolism, vol. 89, no. 6, pp. 27282735, 2004.

[74] G. Wang, J. Wei, Y. Guan, N. Jin, J. Mao, and X. Wang, "Peroxisome proliferator-activated receptor- $\gamma$ agonist rosiglitazone reduces clinical inflammatory responses in type 2 diabetes with coronary artery disease after coronary angioplasty," Metabolism, vol. 54, no. 5, pp. 590-597, 2005.

[75] R. Agarwal, "Anti-inflammatory effects of short-term pioglitazone therapy in men with advanced diabetic nephropathy," American Journal of Physiology, vol. 290, no. 3, pp. F600F605, 2006.

[76] K. Muranaka, Y. Yanagi, Y. Tamaki, et al., "Effects of peroxisome proliferator-activated receptor $\gamma$ and its ligand on blood-retinal barrier in a streptozotocin-induced diabetic model," Investigative Ophthalmology \& Visual Science, vol. 47, no. 10, pp. 4547-4552, 2006.

[77] N. Toda and M. Nakanishi-Toda, "Nitric oxide: ocular blood flow, glaucoma, and diabetic retinopathy," Progress in Retinal and Eye Research, vol. 26, no. 3, pp. 205-238, 2007.

[78] D.-H. Cho, Y. J. Choi, S. A. Jo, and I. Jo, "Nitric oxide production and regulation of endothelial nitricoxide synthase phosphorylation by prolonged treatment with troglitazone: evidence for involvement of peroxisome proliferator-activated receptor (PPAR) $\gamma$-dependent and PPAR $\gamma$-independent signaling pathways," Journal of Biological Chemistry, vol. 279, no. 4, pp. 2499-2506, 2004.

[79] A. Bernardo, G. Levi, and L. Minghetti, "Role of the peroxisome proliferator-activated receptor- $\gamma$ (PPAR- $\gamma$ ) and its natural ligand 15-deoxy- $\Delta^{12,14}$-prostaglandin $\mathrm{J}_{2}$ in the regulation of microglial functions," European Journal of Neuroscience, vol. 12, no. 7, pp. 2215-2223, 2000.

[80] A. Bernardo, M. A. Ajmone-Cat, L. Gasparini, E. Ongini, and L. Minghetti, "Nuclear receptor peroxisome proliferatoractivated receptor- $\gamma$ is activated in rat microglial cells by the anti-inflammatory drug HCT1026, a derivative of flurbiprofen," Journal of Neurochemistry, vol. 92, no. 4, pp. 895-903, 2005.

[81] J. Kim, Y.-S. Oh, and S.-H. Shinn, “Troglitazone reverses the inhibition of nitric oxide production by high glucose in cultured bovine retinal pericytes," Experimental Eye Research, vol. 81, no. 1, pp. 65-70, 2005.

[82] K. Adachi, S. Kashii, H. Masai, et al., "Mechanism of the pathogenesis of glutamate neurotoxicity in retinal ischemia," Graefe's Archive for Clinical and Experimental Ophthalmology, vol. 236, no. 10, pp. 766-774, 1998.

[83] C. Kaur, V. Sivakumar, and W. S. Foulds, "Early response of neurons and glial cells to hypoxia in the retina," Investigative Ophthalmology \& Visual Science, vol. 47, no. 3, pp. 11261141, 2006.

[84] K. Yamakawa, M. Hosoi, H. Koyama, et al., "Peroxisome proliferator-activated receptor- $\gamma$ agonists increase vascular endothelial growth factor expression in human vascular smooth muscle cells," Biochemical and Biophysical Research Communications, vol. 271, no. 3, pp. 571-574, 2000.

[85] M. Emoto, T. Anno, Y. Sato, et al., "Troglitazone treatment increases plasma vascular endothelial growth factor in diabetic patients and its mRNA in 3T3-L1 adipocytes," Diabetes, vol. 50, no. 5, pp. 1166-1170, 2001.

[86] V. Chintalgattu, G. S. Harris, S. M. Akula, and L. C. Katwa, "PPAR- $\gamma$ agonists induce the expression of VEGF and its receptors in cultured cardiac myofibroblasts," Cardiovascular Research, vol. 74, no. 1, pp. 140-150, 2007.

[87] T. Baba, K. Shimada, S. Neugebauer, D. Yamada, S. Hashimoto, and T. Watanabe, "The oral insulin sensitizer, 
thiazolidinedione, increases plasma vascular indothelial growth factor in type 2 diabetic patients," Diabetes Care, vol. 24, no. 5, pp. 953-954, 2001.

[88] D. Panigrahy, S. Singer, L. Q. Shen, et al., "PPAR $\gamma$ ligands inhibit primary tumor growth and metastasis by inhibiting angiogenesis," Journal of Clinical Investigation, vol. 110, no. 7, pp. 923-932, 2002.

[89] J. Varet, L. Vincent, P. Mirshahi, et al., "Fenofibrate inhibits angiogenesis in vitro and in vivo," Cellular and Molecular Life Sciences, vol. 60, no. 4, pp. 810-819, 2003.

[90] T. Murata, S. He, M. Hangai, et al., "Peroxisome proliferatoractivated receptor- $\gamma$ ligands inhibit choroidal neovascularization," Investigative Ophthalmology \& Visual Science, vol. 41, no. 8, pp. 2309-2317, 2000.

[91] T. Murata, Y. Hata, T. Ishibashi, et al., "Response of experimental retinal neovascularization to thiazolidinediones," Archives of Ophthalmology, vol. 119, no. 5, pp. 709-717, 2001.

[92] C. Combadière, C. Feumi, W. Raoul, et al., "CX3CR1dependent subretinal microglia cell accumulation is associated with cardinal features of age-related macular degeneration," Journal of Clinical Investigation, vol. 117, no. 10, pp. 2920-2928, 2007.

[93] P. J. Keck, S. D. Hauser, G. Krivi, et al., "Vascular permeability factor, an endothelial cell mitogen related to PDGF," Science, vol. 246, no. 4935, pp. 1309-1312, 1989.

[94] D. W. Leung, G. Cachianes, W.-J. Kuang, D. V. Goeddel, and N. Ferrara, "Vascular endothelial growth factor is a secreted angiogenic mitogen," Science, vol. 246, no. 4935, pp. 1306 1309, 1989.

[95] J. Tombran-Tink, G. G. Chader, and L. V. Johnson, "PEDF: a pigment epithelium-derived factor with potent neuronal differentiative activity," Experimental Eye Research, vol. 53, no. 3, pp. 411-414, 1991.

[96] D. W. Dawson, O. V. Volpert, P. Gillis, et al., "Pigment epithelium-derived factor: a potent inhibitor of angiogenesis," Science, vol. 285, no. 5425, pp. 245-248, 1999.

[97] A. Afzal, L. C. Shaw, A. V. Ljubimov, M. E. Boulton, M. S. Segal, and M. B. Grant, "Retinal and choroidal microangiopathies: therapeutic opportunities," Microvascular Research, vol. 74, no. 2-3, pp. 131-144, 2007.

[98] J. S. L. Tan, P. Mitchell, A. Kifley, V. Flood, W. Smith, and J. J. Wang, "Smoking and the long-term incidence of agerelated macular degeneration: the blue mountains eye study," Archives of Ophthalmology, vol. 125, no. 8, pp. 1089-1095, 2007.

[99] J. P. SanGiovanni, E. Y. Chew , T. E. Clemons, et al., "The relationship of dietary lipid intake and age-related macular degeneration in a case-control study: AREDS report no. 20," Archives of Ophthalmology, vol. 125, no. 5, pp. 671-679, 2007.

[100] A. O. Edwards, R. Ritter III, K. J. Abel, A. Manning, C. Panhuysen, and L. A. Farrer, "Complement factor H polymorphism and age-related macular degeneration," Science, vol. 308, no. 5720, pp. 421-424, 2005.

[101] G. S. Hageman, D. H. Anderson, L. V. Johnson, et al., "A common haplotype in the complement regulatory gene factor $\mathrm{H}$ $(H F 1 / C F H)$ predisposes individuals to age-related macular degeneration," Proceedings of the National Academy of Sciences of the United States of America, vol. 102, no. 20, pp. 7227-7232, 2005.

[102] J. L. Haines, M. A. Hauser, S. Schmidt, et al., "Complement factor $\mathrm{H}$ variant increases the risk of age-related macular degeneration," Science, vol. 308, no. 5720, pp. 419-421, 2005.

[103] J. Tuo, B. C. Smith, C. M. Bojanowski, et al., "The involvement of sequence variation and expression of CX3CR1 in the pathogenesis of age-related macular degeneration," The FASEB Journal, vol. 18, no. 11, pp. 1297-1299, 2004.

[104] J. M. Seddon, S. George, B. Rosner, and N. Rifai, "Progression of age-related macular degeneration: prospective assessment of C-reactive protein, interleukin 6, and other cardiovascular biomarkers," Archives of Ophthalmology, vol. 123, no. 6, pp. 774-782, 2005.

[105] K. Izumi-Nagai, N. Nagai, Y. Ozawa, et al., "Interleukin-6 receptor-mediated activation of signal transducer and activator of transcription-3 (STAT3) promotes choroidal neovascularization," American Journal of Pathology, vol. 170, no. 6, pp. 2149-2158, 2007.

[106] D. H. Anderson, R. F. Mullins, G. S. Hageman, and L. V. Johnson, "A role for local inflammation in the formation of drusen in the aging eye," American Journal of Ophthalmology, vol. 134, no. 3, pp. 411-431, 2002.

[107] R. F. Mullins, S. R. Russell, D. H. Anderson, and G. S. Hageman, "Drusen associated with aging and age-related macular degeneration contain proteins common to extracellular deposits associated with atherosclerosis, elastosis, amyloidosis, and dense deposit disease," The FASEB Journal, vol. 14, no. 7, pp. 835-846, 2000.

[108] G. S. Hageman, P. J. Luthert, N. H. Victor Chong, L. V. Johnson, D. H. Anderson, and R. F. Mullins, "An integrated hypothesis that considers drusen as biomarkers of immunemediated processes at the RPE-Bruch's membrane interface in aging and age-related macular degeneration," Progress in Retinal and Eye Research, vol. 20, no. 6, pp. 705-732, 2001.

[109] M. Nozaki, B. J. Raisler, E. Sakurai, et al., "Drusen complement components C3a and C5a promote choroidal neovascularization," Proceedings of the National Academy of Sciences of the United States of America, vol. 103, no. 7, pp. 2328-2333, 2006.

[110] B. Martini and S. J. Ryan, "Argon laser lesions of the retina; occurrence and origin of macrophages," European Journal of Ophthalmology, vol. 2, no. 2, pp. 51-57, 1992.

[111] P. L. Penfold, M. C. Madigan, M. C. Gillies, and J. M. Provis, "Immunological and aetiological aspects of macular degeneration," Progress in Retinal and Eye Research, vol. 20, no. 3, pp. 385-414, 2001.

[112] N. Gupta, K. E. Brown, and A. H. Milam, "Activated microglia in human retinitis pigmentosa, late-onset retinal degeneration, and age-related macular degeneration," Experimental Eye Research, vol. 76, no. 4, pp. 463-471, 2003.

[113] S. Thanos, "Sick photoreceptors attract activated microglia from the ganglion cell layer: a model to study the inflammatory cascades in rats with inherited retinal dystrophy," Brain Research, vol. 588, no. 1, pp. 21-28, 1992.

[114] R. S. Roque, C. J. Imperial, and R. B. Caldwell, "Microglial cells invade the outer retina as photoreceptors degenerate in Royal College of Surgeons rats," Investigative Ophthalmology \& Visual Science, vol. 37, no. 1, pp. 196-203, 1996.

[115] D. G. Espinosa-Heidmann, A. Caicedo, E. P. Hernandez, K. G. Csaky, and S. W. Cousins, "Bone marrow-derived progenitor cells contribute to experimental choroidal neovascularization," Investigative Ophthalmology \& Visual Science, vol. 44, no. 11, pp. 4914-4919, 2003.

[116] E. Sakurai, A. Anand, B. K. Ambati, N. van Rooijen, and J. Ambati, "Macrophage depletion inhibits experimental choroidal neovascularization," Investigative Ophthalmology \& Visual Science, vol. 44, no. 8, pp. 3578-3585, 2003.

[117] D. G. Espinosa-Heidmann, I. J. Suner, E. P. Hernandez, D. Monroy, K. G. Csaky, and S. W. Cousins, "Macrophage depletion diminishes lesion size and severity in experimental 
choroidal neovascularization," Investigative Ophthalmology \& Visual Science, vol. 44, no. 8, pp. 3586-3592, 2003.

[118] J. Ambati, A. Anand, S. Fernandez, et al., "An animal model of age-related macular degeneration in senescent Ccl-2- or Ccr-2-deficient mice," Nature Medicine, vol. 9, no. 11, pp. 1390-1397, 2003.

[119] H. Oh, H. Takagi, C. Takagi, et al., "The potential angiogenic role of macrophages in the formation of choroidal neovascular membranes," Investigative Ophthalmology \& Visual Science, vol. 40, no. 9, pp. 1891-1898, 1999.

[120] V. M. Elner, R. M. Strieter, S. G. Elner, M. Baggiolini, I. Lindley, and S. L. Kunkel, "Neutrophil chemotactic factor (IL-8) gene expression by cytokine-treated retinal pigment epithelial cells," American Journal of Pathology, vol. 136, no. 4, pp. 745-750, 1990.

[121] Z.-M. Bian, S. G. Elner, R. M. Strieter, S. L. Kunkel, N. W. Lukacs, and V. M. Elner, "IL-4 potentiates IL- $1 \beta$ - and TNF$\alpha$-stimulated IL- 8 and MCP- 1 protein production in human retinal pigment epithelial cells," Current Eye Research, vol. 18, no. 5, pp. 349-357, 1999.

[122] S. G. Elner, R. M. Strieter, V. M. Elner, B. J. Rollins, M. A. Del Monte, and S. L. Kunkel, "Monocyte chemotactic protein gene expression by cytokine-treated human retinal pigment epithelial cells," Laboratory Investigation, vol. 64, no. 6, pp. 819-825, 1991.

[123] H. E. Grossniklaus, J. X. Ling, T. M. Wallace, et al., "Macrophage and retinal pigment epithelium expression of angiogenic cytokines in choroidal neovascularization," Molecular Vision, vol. 8, pp. 119-126, 2002.

[124] M. Meissner, M. Stein, C. Urbich, et al., "PPAR $\alpha$ activators inhibit vascular endothelial growth factor receptor-2 expression by repressing Sp1-dependent DNA binding and transactivation," Circulation Research, vol. 94, no. 3, pp. 324-332, 2004.

[125] L. Piqueras, A. R. Reynolds, K. M. Hodivala-Dilke, et al., "Activation of PPAR $\beta / \delta$ induces endothelial cell proliferation and angiogenesis," Arteriosclerosis, Thrombosis, and Vascular Biology, vol. 27, no. 1, pp. 63-69, 2007.

[126] S. Qin, A. P. McLaughlin, and G. W. De Vries, "Protection of RPE cells from oxidative injury by 15 -deoxy- $\Delta^{12,14}$ prostaglandin $\mathrm{J}_{2}$ by augmenting GSH and activating MAPK," Investigative Ophthalmology \& Visual Science, vol. 47, no. 11, pp. 5098-5105, 2006.

[127] P. Shashkin, B. Dragulev, and K. Ley, "Macrophage differentiation to foam cells," Current Pharmaceutical Design, vol. 11, no. 23, pp. 3061-3072, 2005.

[128] K. H. Han, J. Ryu, K. H. Hong, et al., "HMG-CoA reductase inhibition reduces monocyte CC chemokine receptor 2 expression and monocyte chemoattractant protein-1-mediated monocyte recruitment in vivo," Circulation, vol. 111, no. 11, pp. 1439-1447, 2005.

[129] M. Niino, K. Iwabuchi, S. Kikuchi, et al., "Amelioration of experimental autoimmune encephalomyelitis in C57BL/6 mice by an agonist of peroxisome proliferator-activated receptor$\gamma$, Journal of Neuroimmunology, vol. 116, no. 1, pp. 40-48, 2001.

[130] C. Natarajan and J. J. Bright, "Peroxisome proliferatoractivated receptor- $\gamma$ agonist inhibit experimental allergic encephalomyelitis by blocking IL-12 production, IL-12 signaling and Th1 differentiation," Genes \& Immunity, vol. 3, no. 2, pp. 59-70, 2002.

[131] A. Diab, C. Deng, J. D. Smith, et al., "Peroxisome proliferatoractivated receptor- $\gamma$ agonist 15 -deoxy- $\Delta^{12,14}$-prostaglandin $\mathrm{J}_{2}$ ameliorates experimental autoimmune encephalomyelitis," Journal of Immunology, vol. 168, no. 5, pp. 2508-2515, 2002.

[132] D. L. Feinstein, E. Galea, V. Gavrilyuk, et al., "Peroxisome proliferator-activated receptor- $\gamma$ agonists prevent experimental autoimmune encephalomyelitis," Annals of Neurology, vol. 51, no. 6, pp. 694-702, 2002.

[133] A. E. Lovett-Racke, R. Z. Hussain, S. Northrop, et al., "Peroxisome proliferator-activated receptor $\alpha$ agonists as therapy for autoimmune disease," Journal of Immunology, vol. 172, no. 9, pp. 5790-5798, 2004.

[134] P. E. Polak, S. Kalinin, C. Dello Russo, et al., "Protective effects of a peroxisome proliferator-activated receptor- $\beta / \delta$ agonist in experimental autoimmune encephalomyelitis," Journal of Neuroimmunology, vol. 168, no. 1-2, pp. 65-75, 2005.

[135] H. P. Raikwar, G. Muthian, J. Rajasingh, C. N. Johnson, and J. J. Bright, "PPAR $\gamma$ antagonists reverse the inhibition of neural antigen-specific Th1 response and experimental allergic encephalomyelitis by Ciglitazone and 15-Deoxy- $\Delta^{12,14}$ prostaglandin $\mathrm{J}_{2}$," Journal of Neuroimmunology, vol. 178, no. 1-2, pp. 76-86, 2006.

[136] S. Dasgupta, A. Roy, M. Jana, D. M. Hartley, and K. Pahan, "Gemfibrozil ameliorates relapsing-remitting experimental autoimmune encephalomyelitis independent of peroxisome proliferator-activated receptor- $\alpha$," Molecular Pharmacology, vol. 72, no. 4, pp. 934-946, 2007.

[137] M. Peiris, G. R. Monteith, S. J. Roberts-Thomson, and P. J. Cabot, "A model of experimental autoimmune encephalomyelitis (EAE) in C57BL/6 mice for the characterisation of intervention therapies," Journal of Neuroscience Methods, vol. 163, no. 2, pp. 245-254, 2007.

[138] M. Matiello, A. Jacob, D. M. Wingerchuk, and B. G. Weinshenker, "Neuromyelitis optica," Current Opinion in Neurology, vol. 20, no. 3, pp. 255-260, 2007.

[139] A. Jacob, M. Matiello, D. M. Wingerchuk, C. F. Lucchinetti, S. J. Pittock, and B. G. Weinshenker, "Neuromyelitis optica: changing concepts," Journal of Neuroimmunology, vol. 187, no. 1-2, pp. 126-138, 2007.

[140] S. L. Galetta and J. Bennett, "Neuromyelitis optica is a variant of multiple sclerosis," Archives of Neurology, vol. 64, no. 6, pp. 901-903, 2007.

[141] M. K. Storch, A. Stefferl, U. Brehm, et al., "Autoimmunity to myelin oligodendrocyte glycoprotein in rats mimics the spectrum of multiple sclerosis pathology," Brain Pathology, vol. 8, no. 4, pp. 681-694, 1998.

[142] E. Bettelli, "Building different mouse models for human MS," Annals of the New York Academy of Sciences, vol. 1103, pp. 1118, 2007.

[143] E. Bettelli, M. Pagany, H. L. Weiner, C. Linington, R. A. Sobel, and V. K. Kuchroo, "Myelin oligodendrocyte glycoproteinspecific $\mathrm{T}$ cell receptor transgenic mice develop spontaneous autoimmune optic neuritis," Journal of Experimental Medicine, vol. 197, no. 9, pp. 1073-1081, 2003.

[144] S. Dhib-Jalbut, "Pathogenesis of myelin/oligodendrocyte damage in multiple sclerosis," Neurology, vol. 68, no. 22, supplement 3, pp. S13-S21, 2007, discussion S43-S54.

[145] P. Sanders and J. De Keyser, "Janus faces of microglia in multiple sclerosis," Brain Research Reviews, vol. 54, no. 2, pp. 274 285, 2007.

[146] A. Diab, R. Z. Hussain, A. E. Lovett-Racke, J. A. Chavis, P. D. Drew, and M. K. Racke, "Ligands for the peroxisome proliferator-activated receptor- $\gamma$ and the retinoid $\mathrm{X}$ receptor exert additive anti-inflammatory effects on experimental autoimmune encephalomyelitis," Journal of Neuroimmunology, vol. 148, no. 1-2, pp. 116-126, 2004. 
[147] P. D. Storer, J. Xu, J. A. Chavis, and P. D. Drew, "Peroxisome proliferator-activated receptor- $\gamma$ agonists inhibit the activation of microglia and astrocytes: implications for multiple sclerosis," Journal of Neuroimmunology, vol. 161, no. 1-2, pp. 113-122, 2005.

[148] J. Xu, M. K. Racke, and P. D. Drew, "Peroxisome proliferatoractivated receptor- $\alpha$ agonist fenofibrate regulates IL- 12 family cytokine expression in the CNS: relevance to multiple sclerosis," Journal of Neurochemistry, vol. 103, no. 5, pp. 18011810, 2007.

[149] P. D. Storer, J. Xu, J. A. Chavis, and P. D. Drew, "Cyclopentenone prostaglandins $\mathrm{PGA}_{2}$ and 15 -deoxy- $\Delta^{12,14} \mathrm{PGJ}_{2}$ suppress activation of marine microglia and astrocytes: implications for multiple sclerosis," Journal of Neuroscience Research, vol. 80, no. 1, pp. 66-74, 2005.

[150] J. Xu and P. D. Drew, "Peroxisome proliferator-activated receptor- $\gamma$ agonists suppress the production of IL-12 family cytokines by activated glia," Journal of Immunology, vol. 178, no. 3, pp. 1904-1913, 2007.

[151] R. Luna-Medina, M. Cortes-Canteli, M. Alonso, A. Santos, A. Martínez, and A. Perez-Castillo, "Regulation of inflammatory response in neural cells in vitro by thiadiazolidinones derivatives through peroxisome proliferator-activated receptor $\gamma$ activation," Journal of Biological Chemistry, vol. 280, no. 22, pp. 21453-21462, 2005.

[152] J. Xu, P. D. Storer, J. A. Chavis, M. K. Racke, and P. D. Drew, "Agonists for the peroxisome proliferator-activated receptor$\alpha$ and the retinoid $\mathrm{X}$ receptor inhibit inflammatory responses of microglia," Journal of Neuroscience Research, vol. 81, no. 3, pp. 403-411, 2005.

[153] H. A. Pershadsingh, M. T. Heneka, R. Saini, N. M. Amin, D. J. Broeske, and D. L. Feinstein, "Effect of pioglitazone treatment in a patient with secondary multiple sclerosis," Journal of Neuroinflammation, vol. 1, p. 3, 2004.

[154] A. Matteucci, G. Formisano, S. Paradisi, et al., "Biocompatibility assessment of liquid artificial vitreous replacements: relevance of in vitro studies," Survey of Ophthalmology, vol. 52, no. 3, pp. 289-299, 2007. 


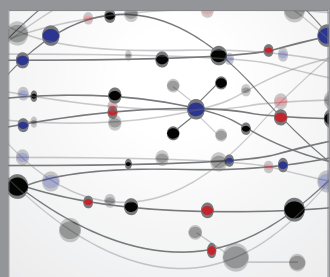

The Scientific World Journal
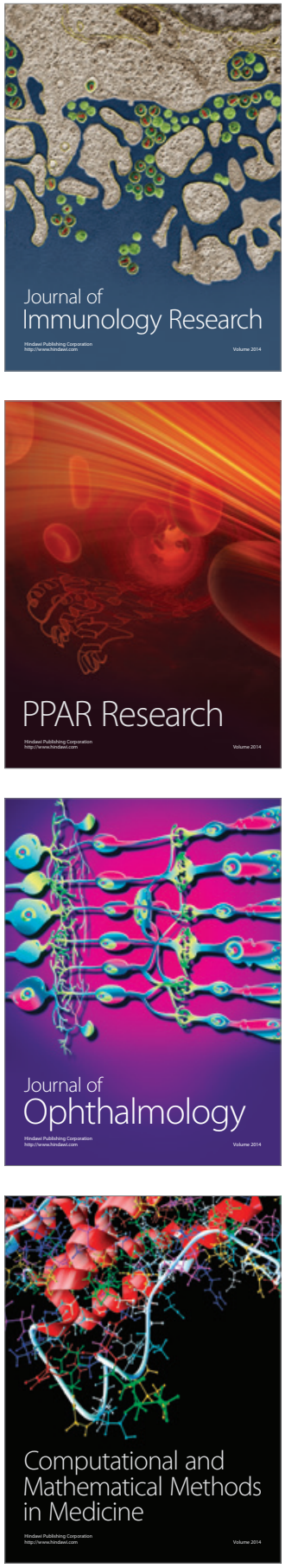

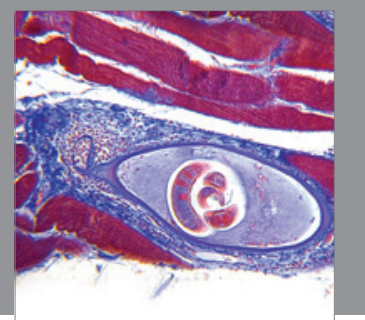

Gastroenterology

Research and Practice
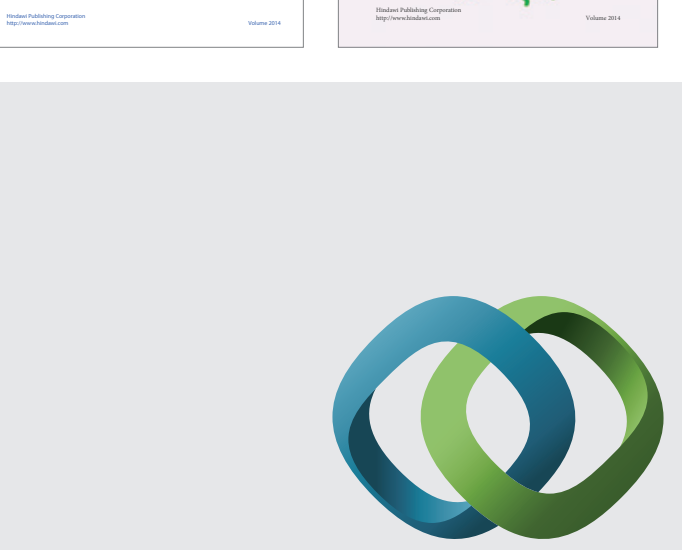

\section{Hindawi}

Submit your manuscripts at

http://www.hindawi.com
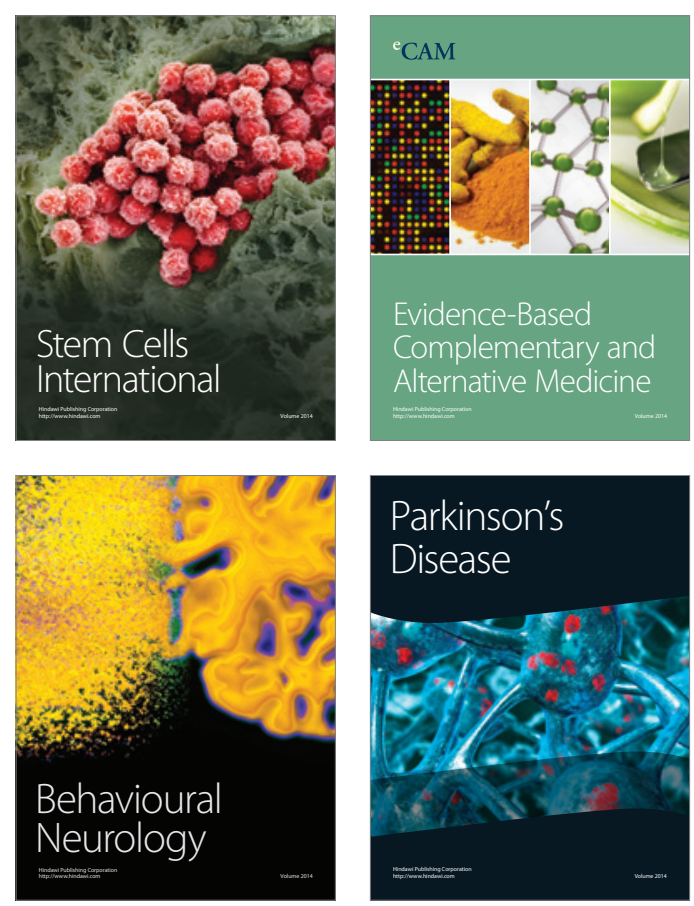

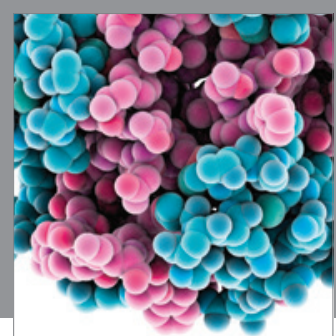

Journal of
Diabetes Research

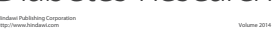

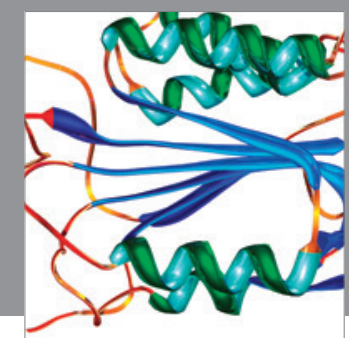

Disease Markers
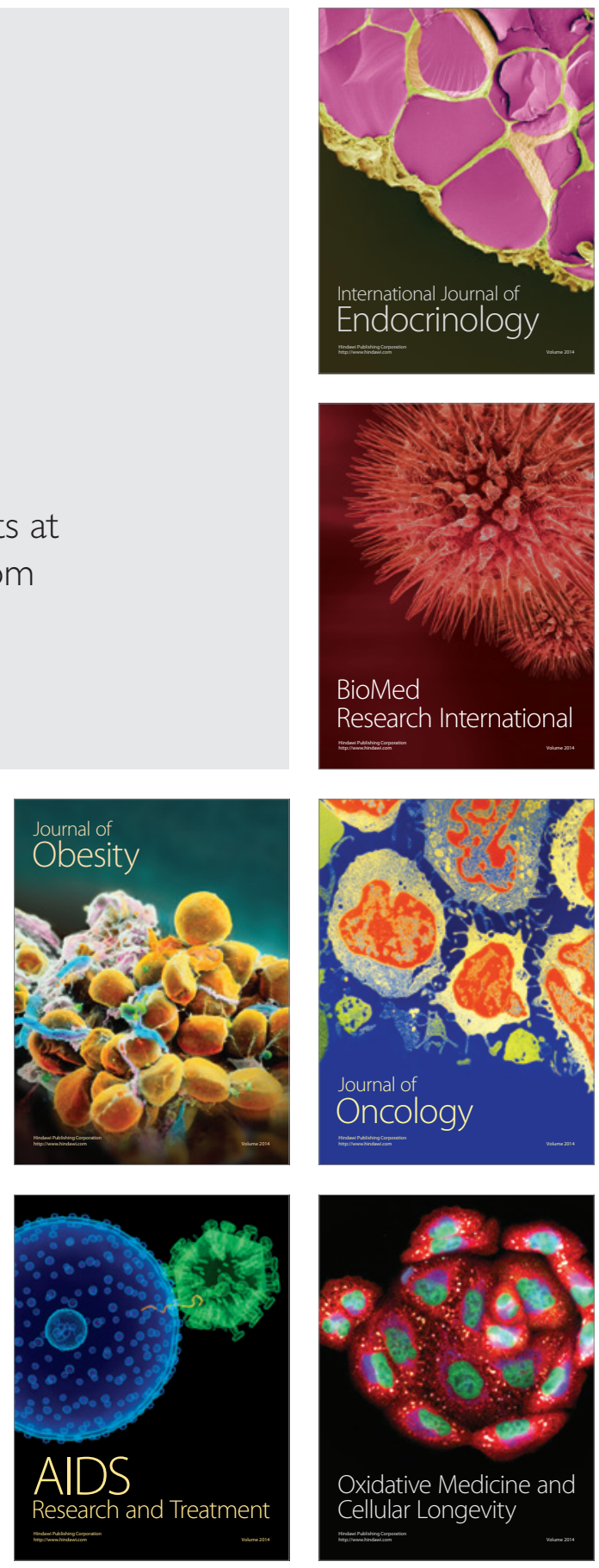